\title{
Determination of Trace Metals in Biological Samples by Inductively Coupled Plasma Atomic Emission Spectrometry with Discrete Nebulization after Microwave Decomposition
}

\author{
Hirofumi Isoyama, Tetsuo Uchida, Kyoko Oguchi, Chuzo IIDA and Genkichi Nakagawa \\ Department of Applied Chemistry, Nagoya Institute of Technology, Gokiso, Showa, Nagoya 466, Japan
}

\begin{abstract}
Trace metals in some biological samples were measured by the discrete nebulization technique in inductively coupled plasma atomic emission spectrometry. The small spray chamber and the time-sharing background correction system were used for the rapid measurements. Small amounts of the samples were decomposed quickly in a sealed PTFE vessel in a microwave oven. The analytical results for $\mathrm{Al}, \mathrm{Cu}, \mathrm{Fe}, \mathrm{Mn}$ and $\mathrm{Zn}$ agreed well with the certified values and also with those obtained by continuous nebulization.
\end{abstract}

Keywords Inductively coupled plasma atomic emission spectrometry, discrete nebulization, small spray chamber, time-sharing background correction, microwave sample decomposition

The discrete nebulization technique is favorable for minute samples, such as biological and clinical samples, not only in atomic absorption spectrometry ${ }^{1}$ but also in inductively coupled plasma atomic emission spectrometry (ICP-AES). ${ }^{2-6}$ The smaller the sample volume becomes, the more essential this technique is. With large spray chamber equipped in commercial ICP-AE spectrometers, however, the sensitivity and precision in discrete nebulization with smaller sample volume, e.g., less than $100 \mathrm{~mm}^{3}$, were inferior to those in continuous nebulization, due to the slow response of signals. Fortunately, the slow response was improved significantly by using the small spray chamber..$^{7-9}$

The background correction should be essential for the samples giving background to obtain the reliable results. Considering structured background spectra, the point for background correction is desirable as close as possible to the center of the analysis line, so that the difference in the background intensities at the center and at the correcting point can be negligible. A pair of separate measurements is required for the background correction at the center and wing of analysis line with a single channel spectrometer. In the discrete nebulization, this background correction needs tedious and time-consuming duplicate measurements, and double volumes of sample are required. Thus, a time-sharing background correction would be desirable in the discrete nebulization, because the pseudo-simultaneous measurements of peak and background was possible at short intervals using a vibrating quartz plate..$^{10-12}$

In the present work, the combination of a small spray chamber ${ }^{9}$ and time-sharing background correction system ${ }^{12}$ was applied successfully for the determination of trace metals ( $\mathrm{Al}, \mathrm{Cu}, \mathrm{Fe}, \mathrm{Mn}$ and $\mathrm{Zn}$ ) in some biological samples after the decomposition with a sealed PTFE vessel in a microwave oven. The continuous nebulization was also used for the comparison of analytical results.

\section{Experimental}

\section{Apparatus and equipments}

The Nippon Jarrel-Ash ICP-AE spectrometer, Model ICAP-575, was operated under the conditions listed in Table 1. The photomultipliers (Hamamatsu Photonics) used were R-500 of wide range and R-427 of solar-blind types. The higher orders of analysis lines were used for

\section{Table 1 Operating conditions for ICAP-575}

\begin{tabular}{ll} 
RF power & $1.2 \mathrm{~kW}$ \\
Coolant Ar flow rate & $16 \mathrm{dm}^{3} \mathrm{~min}^{-1}$ \\
Plasma Ar flow rate & $0.6 \mathrm{dm}^{3} \mathrm{~min}^{-1}$ \\
Carrier Ar flow rate & $0.48 \mathrm{dm}^{3} \mathrm{~min}^{-1}\left(1.5 \mathrm{~kg} \mathrm{~cm}^{-2}\right)$ \\
Sample aspiration rate & $2.6 \mathrm{~cm}^{3} \mathrm{~min}^{-1}$ \\
Slit width & $25 \mu \mathrm{m}$ \\
Observation height & $12.5 \mathrm{~mm}$ \\
Photomultiplier tube & R-500 for Al, Cu \\
& R-427 for Fe, Mn, Zn \\
Integration time & $3 \mathrm{~s}$ for continuous mode \\
& $7 \mathrm{~s} \mathrm{for} \mathrm{discrete} \mathrm{mode}$ \\
Analysis line & Al I $396.152 \mathrm{~nm}$ \\
& Cu I $324.754 \mathrm{~nm}$ \\
& Fe II $238.204 \mathrm{~nm} \times 2$ \\
& $\mathrm{Mn} \mathrm{Il} 257.610 \mathrm{~nm} \times 2$ \\
& $\mathrm{Zn} \mathrm{I} 213.856 \mathrm{~nm} \times 3$ \\
\hline
\end{tabular}


$\mathrm{Fe}, \mathrm{Mn}$ and $\mathrm{Zn}$ to avoid spectral interferences and to get good signal-to-background ratios in conjunction with the solar-blind photomultiplier. With a cross-flow nebulizer, the small spray chamber of $1.8 \mathrm{~cm}$ internal diameter and $5 \mathrm{~cm}$ long' was replaced by a commercially available large chamber.

The time-sharing background correction system consisted of a quartz plate $2 \mathrm{~mm}$ thick in an optical path. The vibrating frequency of the plate was improved to 28.5 Hz from $6.7 \mathrm{~Hz}$ in the previous work ${ }^{12}$ for better precision. In the first quarter of the period, the plate was scanned and stabilized. The center signal was sampled in the second quarter. The third and the last quarters were employed for the background signal in a similar manner. The difference of center and background signals, or the net signal, was output through a post amplifier. The background was corrected at longer wavelength side, ca. $0.04 \mathrm{~nm}$ apart from the center of analysis line for each element.

The sample of $50 \mathrm{~mm}^{3}$ was easily aspirated by touching the end of a nebulizer capillary onto the sample drop in the small holes drilled on PTFE block. This aspirating technique for small sample volume was simple and reliable even for unskilled operators. Triplicate nebulizations were carried out both for sample and standard solutions.

The integration of peak-area was gated with the trigger obtained from the photo-coupler across the capillary. ${ }^{13}$ The peak area was integrated for $7 \mathrm{~s}$, and peak-height was measured on a strip-chart recorder. The integration time for continuous nebulization was $9 \mathrm{~s}(3 \mathrm{~s} \times 3)$.

\section{Reagents and sample preparation}

The standard stock solution of $2000 \mu \mathrm{g} \mathrm{g}^{-1}$ for each element was prepared by dissolving ultrapure metal, its salt or oxide in appropriate acids. The stock solutions were mixed and diluted by mass with $0.1 \mathrm{~mol} \mathrm{dm}^{-3}$ perchloric acid for the preparations of working solutions. These working solutions contained trace metals in the concentrations of about $0.5,1.0$ and 1.5-folds of those in sample solutions.

The samples analyzed were Certified Reference Materials (CRM) No. 1 Pepperbush, No. 5 Human Hair, No. 6 Mussel and No. 7 Tea Leaves of National Institute of Environmental Study (NIES), and Standard Reference Material (SRM) 1566 Oyster Tissue of National Institute of Standards and Technology (NIST). After drying of the sample at $85^{\circ} \mathrm{C}$ for $4 \mathrm{~h}$, an aliquot of $150 \mathrm{mg}$ was weighed into a PFA Tuf-Tainer Vial (Pierce, TV-7), and $3 \mathrm{~cm}^{3}$ of nitric, $0.3 \mathrm{~cm}^{3}$ of hydrochloric, $0.3 \mathrm{~cm}^{3}$ of perchloric and $0.15 \mathrm{~cm}^{3}$ of hydrofluoric acids were added. The outer PTFE vessel (San'ai, PT-25) containing TV-7 and $1.5 \mathrm{~cm}^{3}$ of $1 \mathrm{~mol}$ $\mathrm{dm}^{-3}$ sodium hydroxide was tightly sealed with a polypropylene jacket (San'ai, PP-25) with a wrench. The sodium hydroxide solution could partly serve to compensate for the rise in inner pressure, and to absorb acid vapors which leaked from the vial. The schematic

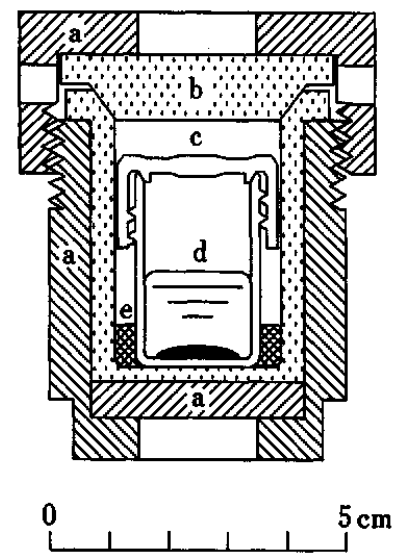

Fig. 1 Sealed PTFE vessel for microwave digestion. a, polypropylene jacket; b, PTFE outer vessel $\left(25 \mathrm{~cm}^{3}\right.$ capacity); c, Teflon PFA inner vessel $\left(7 \mathrm{~cm}^{3}\right.$ capacity); $d$, sample and acid mixture; e, $1 \mathrm{~mol} \mathrm{dm}^{-3} \mathrm{NaOH}$.

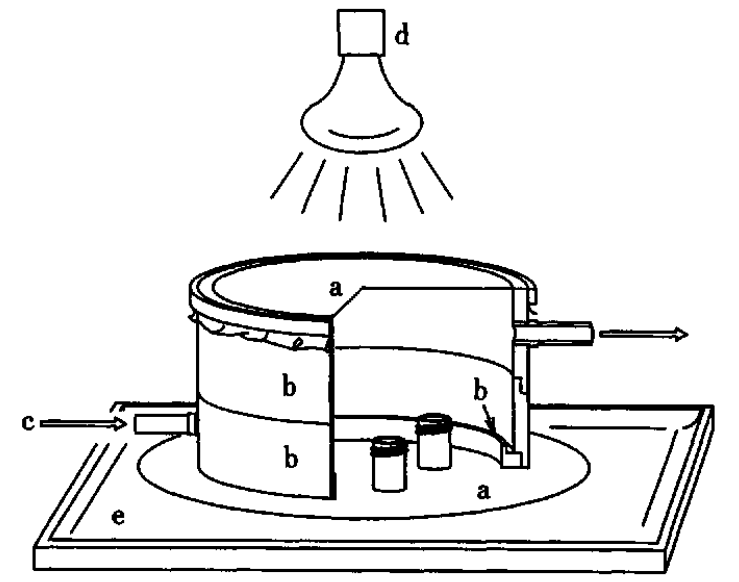

Fig. 2 Evaporation chamber. a, Teflon PFA clear sheet (0.125 mm thick); b, 3-pieces PTFE drum (upper, lower and base); $c$, inlet for filtered air; $d$, infrared lamp ( $375 \mathrm{~W}$ ); e, hot-plate for kitchen use.

diagram of microwave digestion vessel is shown in Fig. 1. A set of four vessels was located symmetrically on a turntable of a microwave oven for kitchen use (Mitsubishi, RO-2500). These samples were heated together with $50 \mathrm{~cm}^{3}$ of water in a beaker placed at the center of the turntable, for $5 \mathrm{~min}$ at intermittent power corresponding to $200 \mathrm{~W}$. After removal of the beaker, the samples were heated again for $3.5 \mathrm{~min} .{ }^{14}$ The water could control the energy absorbed into the acid mixture, and serve for the gentle digestion of a sample. The digested sample in TV-7 was completely evaporated to dryness on a hot-plate for kitchen use under an infrared lamp in the evaporation chamber shown in Fig. 2 to avoid contamination. The air filtered through a disposable capsule filter made by ADVANTEC Toyo, Model CCP-JX-DIH, was passed through the chamber at the flow rate of $c a .4 \mathrm{dm}^{3} \mathrm{~min}^{-1}$. To decompose the sample as completely as possible, $0.5 \mathrm{~cm}^{3}$ of nitric and 
$0.1 \mathrm{~cm}^{3}$ of perchloric acids were added to the residue, and evaporated to dryness again in the same manner. Finally, the residue was dissolved in $15 \mathrm{~g}$ of $0.1 \mathrm{~mol}$ $\mathrm{dm}^{-3}$ perchloric acid, and weighed.

All reagents used were of analytical grade and Milli$Q$ de-ionized water was used throughout.

\section{Results and Discussion}

In preliminary experiments, the spectral profiles for each element were compared; the profile from the sample solution was compared with that from the standard solution containing a single element. The Al emission at $396.152 \mathrm{~nm}$ was affected by the $\mathrm{Ca}$ in samples, and it would cause the Al result to become too high by more than $10 \%$, in particular for Pepperbush. The background correction for $\mathrm{Ca}$ was required. No background and spectral overlapping were observed for the other elements.

To evaluate the discrete nebulization with peakheight and peak-area measurements, the continuous nebulization was also employed as a conventional routine measurement. The analytical results of trace metals for CRMs and SRM were summarized in Table 2, together with the certified or reference values. No procedure blank was detected for any element. Excellent agreement in analytical results was obtained except for $\mathrm{Al}$.

The analytical value of $\mathrm{Al}$ for Tea Leaves was considerably lower than the certified value, and that for Pepperbush was also lower than that in our previous work. ${ }^{12}$ On the other hand, the value for Oyster Tissue agreed well with the certified value, and those for Human Hair and Mussel were consistent with reference values. The lower results for botanical samples may be caused by incomplete sample decomposition, as no significant difference was observed in the analytical results by different measurements such as peak area and height in discrete nebulization and continuous mode. Moreover, remarkable and frequent flickers on the signal chart were observed in continuous mode. A part of the $\mathrm{Al}$ in the solutions might be suspended as nonvisible fine particulates. Previously, these botanical samples were decomposed with a sealed bomb with the acid mixtures similar to the present work, at $90^{\circ} \mathrm{C}$ for $2 \mathrm{~h}$, followed by $140^{\circ} \mathrm{C}$ for $2 \mathrm{~h}$. The results obtained were 614 ppm for Pepperbush ${ }^{12}$ and 775 ppm for Tea

Table 2 Analytical results for reference materials (ppm)

\begin{tabular}{|c|c|c|c|c|c|c|}
\hline Element & Al & $\mathrm{Cu}$ & $\mathrm{Fe}$ & \multicolumn{2}{|l|}{ Mn } & Zn \\
\hline \multicolumn{7}{|c|}{ NIES-CRM No. 1 Pepperbush } \\
\hline Peak area & $519 \pm 13$ & $12.3 \pm 0.7$ & $197 \pm 5$ & $1990 \pm$ & & $333 \pm 3$ \\
\hline Peak height ${ }^{\mathbf{a}}$ & $515 \pm 15$ & $11.7 \pm 0.7$ & $195 \pm 4$ & $1970 \pm$ & & $326 \pm 4$ \\
\hline Continuous & $513 \pm 11$ & $11.7 \pm 0.6$ & $189 \pm 2$ & $1930 \pm$ & & $323 \pm 3$ \\
\hline Certified & - & $12 \pm 1$ & $205 \pm 17$ & $2030 \pm 1$ & & $340 \pm 20$ \\
\hline \multicolumn{7}{|c|}{ NIES-CRM No. 5 Human Hair } \\
\hline Peak area & $227 \pm 3$ & $17.1 \pm 0.9$ & $220 \pm 5$ & $5.6 \pm$ & 0.5 & $172 \pm 5$ \\
\hline Peak height & $228 \pm 8$ & $16.8 \pm 1.0$ & $217 \pm 5$ & $5.3 \pm$ & 0.4 & $160 \pm 3$ \\
\hline Continuous & $226 \pm 5$ & $15.7 \pm 0.2$ & $216 \pm 5$ & $5.2 \pm$ & 0.4 & $164 \pm 1$ \\
\hline Certified & $(240)$ & $16.3 \pm 1.2$ & $225 \pm 9$ & $5.2 \pm$ & 0.3 & $169 \pm 10$ \\
\hline \multicolumn{7}{|c|}{ NIES-CRM No. 6 Mussel } \\
\hline Peak area & $245 \pm 9$ & $5.2 \pm 1.0$ & $156 \pm 6$ & $15.3 \pm$ & 0.4 & $107 \pm 1$ \\
\hline Peak height & $245 \pm 10$ & N.D. ${ }^{b}$ & $157 \pm 3$ & $15.5 \pm$ & 0.1 & $107 \pm 3$ \\
\hline Continuous & $251 \pm 8$ & $5.1 \pm 0.2$ & $154 \pm 4$ & $15.3 \pm$ & 0.2 & $105 \pm 1$ \\
\hline Certified & $(220)$ & $4.9 \pm 0.3$ & $158 \pm 8$ & $16.3 \pm$ & 1.2 & $106 \pm 6$ \\
\hline \multicolumn{7}{|c|}{ NIES-CRM No. 7 Tea Leaves } \\
\hline Peak area & $704 \pm 8$ & $7.0 \pm 0.6$ & $99 \pm 8$ & $664 \pm$ & 10 & $34 \pm 1$ \\
\hline Peak height & $697 \pm 6$ & N.D. & $95 \pm 8$ & $660 \pm$ & 13 & $34 \pm 1$ \\
\hline Continuous & $688 \pm 11$ & $6.7 \pm 0.3$ & $94 \pm 8$ & $649 \pm$ & 4 & $33 \pm 1$ \\
\hline Certified & $775 \pm 20$ & $7.0 \pm 0.3$ & - & $700 \pm$ & 25 & $33 \pm 3$ \\
\hline \multicolumn{7}{|c|}{ NIST-SRM 1566 Oyster Tissue } \\
\hline Peak area & $252 \pm 12$ & $60.4 \pm 0.9$ & $197 \pm 15$ & $16.6 \pm$ & 0.4 & $835 \pm 15$ \\
\hline Peak height & $251 \pm 13$ & $61.0 \pm 0.6$ & $198 \pm 18$ & $16.4 \pm$ & 1.0 & $841 \pm 8$ \\
\hline Continuous & $247 \pm 10$ & $60.3 \pm 0.5$ & $198 \pm 13$ & $16.7 \pm$ & 0.2 & $836 \pm 5$ \\
\hline Certified & $255 \pm 23$ & $63 \pm 2$ & $195 \pm 11$ & $17.0 \pm$ & 1.2 & $854 \pm 24$ \\
\hline
\end{tabular}

a. Discrete nebulization with $50 \mathrm{~mm}^{3}$ sample. b. N.D., not detected. Reference values are in the parentheses. Number of analyses $=6$. 
Leaves. ${ }^{15}$ Therefore, the decomposition in a microwave oven would be insufficient for some elements in botanical samples, though the microwave digestion was undoubtedly rapid and easy. Further study will be required before the present microwave digestion technique can be routinely applied for various types of samples.

With the peak-height mode, $\mathrm{Cu}$ signal for Mussel and Tea Leaves was submerged in baseline noise. However, the $\mathrm{Cu}$ concentration was measured successfully with the peak-area mode, resulting the same value as that with continuous mode.

\section{References}

1. T. Uchida, I. Kojima and C. Iida, Bunseki Kagaku, 27, T44 (1978).

2. S. Greenfield and P. B. Smith, Anal. Chim. Acta, 59, 341 (1972).

3. J. A. C. Broekaert and F. Leis, Anal. Chim. Acta, 109, 73 (1979).

4. T. Ito, H. Kawaguchi and A. Mizuike, Bunseki Kagaku, 29, 332 (1980).

5. H. Uchida, Y. Nojiri, H. Haraguchi and K. Fuwa, Anal.
Chim. Acta, 123, 57 (1981).

6. T. Uchida, I. Kojima and C. Iida, Analyst [London], 111, 791 (1986).

7. T. Ito, E. Nakagawa, H. Kawaguchi and A. Mizuike, Mikrochim. Acta [Wien], 1982, 423.

8. P. L. Kempster, J. F. Van Staden and H. R. Van Vliet, J. Anal. At. Spectrom., 2, 823 (1987).

9. H. Isoyama, T. Uchida, T. Niwa, C. Iida and G. Nakagawa, J. Anal. At. Spectrom., 4, 351 (1989).

10. W. Snelleman, T. C. Rains, K. W. Yee, H. D. Cook and O. Menis, Anal. Chem., 42, 394 (1970).

11. H. Kawaguchi, M. Okada, T. Ito and A. Mizuike, Anal. Chim. Acta, 95, 145 (1977).

12. H. Isoyama, T. Uchida, C. Iida, G. Nakagawa, Y. Matano, T. Ooe, S. Hamada, H. Iwata and K. Goto, Anal. Sci., 5, 49 (1989).

13. K. Goto, T. Uchida and C. Iida, Rev. Sci. Instrum., 54, 291 (1983).

14. 1. Kojima, T. Uchida and C. Iida, Anal. Sci., 4, 211 (1988).

15. I. Kojima, T. Uchida and C. Iida, Anal. Sci., 2, 225 (1986).

(Received January 22, 1990)

(Accepted February 26, 1990) 